\title{
A scanning electrochemical microscopy characterization of the localized corrosion reactions occurring on nitinol in saline solution after anodic polarization
}

\author{
Abdelilah Asserghine ${ }^{1}$, Martina Medvidović-Kosanović ${ }^{3}$, Anamarija Stanković ${ }^{3}$, Lívia \\ Nagy $^{1,2}$, Ricardo M. Souto ${ }^{4}$, Géza Nagy ${ }^{1,2}$ \\ ${ }^{1}$ Department of General and Physical Chemistry, Faculty of Sciences, University of Pécs, 7624, \\ Ifjúság u. 6. Pécs, Hungary

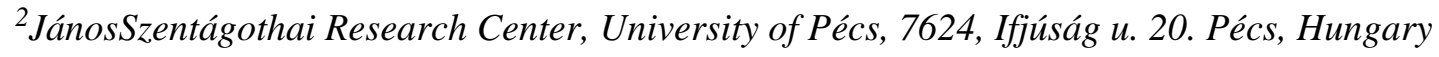 \\ ${ }^{3}$ Department of Chemistry, University of Osijek, Cara Hadrijana 8A, HR-31 000 Osijek, Croatia \\ ${ }^{4}$ Institute of Material Science and Nanotechnology, University of La Laguna, P.O. Box 456, E-38200 \\ La Laguna, Tenerife, Canary Islands, Spain
}

\begin{abstract}
Scanning electrochemical microscopy (SECM) in combined amperometric/potentiometric operation was employed to characterize the electrochemical activity of nitinol biomaterial, prior and after anodic treatment, in $0.1 \mathrm{M} \mathrm{NaCl}$ solution. SECM operation in the feedback mode proved that the nitinol surface was homogeneously passive following surface finishing and storage in ambient condition, whereas heterogeneous surface characteristics occurred after the application of anodic polarization even for a limited time. That is, the development of anodic and cathodic sites owing to the onset of localized corrosion processes was detected on the metal surface. Hydrogen gas evolution from localized sites was monitored using SECM in the substrate generation/tip collection mode (SG/TC), whereas SECM operated in potentiometric mode was used to map the $\mathrm{pH}$ distribution in the electrolyte volume adjacent to the nitinol surface. Local acidification around anodic spots related to $\mathrm{Ni}^{2+}$ discharge, as well as alkalization above the cathodic areas were observed.
\end{abstract}

\section{Keywords:}

Scanning electrochemical microscopy; nitinol; passivity breakdown; antimony microelectrode; localized corrosion; hydrogen evolution. 


\section{Introduction}

Nitinol (NiTi) is a nearly equiatomic alloy of nickel and titanium [1]. Due to its anticorrosion character and unique mechanical properties such as shape memory and superelasticity, it gained extensive applications especially in different fields of health care. It is broadly employed in orthodontic treatments, stents and orthopedic surgery [2-4], because it exhibits excellent mechanical compatibility with living tissues [5,6].

The corrosion resistance of nitinol in aggressive physiological environments arises from the protective passive layer formed spontaneously at its surface [7], which is mostly composed of $\mathrm{TiO}_{2}$ and $\mathrm{NiO}$ [8]. These oxides provide high passivity by inhibiting the electron transfer reactions and the release of hazardous metal cations to the physiological environment $[9,10]$. However, the passivity potential range of nitinol is narrower than for pure titanium. That is, while the passivity range of titanium can extend up to $10 \mathrm{~V}$ vs. SHE [11], the passivity breakdown of nitinol may occur between 0.2 and $1.0 \mathrm{~V}_{\text {SHE }}$ depending on the surface preparation, sample size, and electrolyte composition [8,12,13], a feature making nitinol susceptible to localized corrosion processes such as pitting corrosion [14].

In general, biomaterials can suffer localized corrosion when exposed to physiological environments with high chloride or fluoride concentration, as well as low $\mathrm{pH}$ [15]. In addition, it has been reported that positive potentials up to $+0.64 \mathrm{~V}_{\text {SHE }}$ are spontaneously developed in the human body [16], thus well into the anodic polarization range of biomaterials. Reviews describing the corrosion of nitinol corrosion and the problems associated to its onset are available in the scientific literature $[17,18]$. Recently, in vivo pitting corrosion on implanted nitinol stents has been described by Sullivan et al. [19]. In addition, localized corrosion damage can also occur as a result of mechanical impacts as in the case of fretting corrosion in biomaterials [20-22], and it has been documented for nitinol in particular [23]. On the other hand, the release of $\mathrm{Ni}^{2+}$ ionic species from exposed nitinol in acidic and even in neutral physiological environment was reported [24,25], which is a matter of concern $\mathrm{Ni}^{2+}$ can be a source of allergic reactions and nephro-toxicity in various doses [26-27]. Thus, it is necessary to investigate in situ the local electrochemical properties and the corrosion mechanisms of nitinol in order to improve its corrosion resistance and stability.

Recent works have shown that scanning electrochemical microscopy (SECM) is a very powerful in situ tool for the characterization of the metal surfaces with high spatial resolution, especially in regards to gathering more detailed views of the processes involved in their electrochemical stability as well as the onset of corrosion reactions [29], and the 
characterization of passive metals in particular [30]. Thus, this technique has been employed to investigate the electrochemical reactivity of surface layers [31-34], to detect the nucleation sites of pitting corrosion [35-37], and to map heterogeneous distributions of reactive sites and the release of different species in titanium and titanium alloys [38-41]. More recently, the kinetics of both the self-healing of the passive oxide film of titanium [42,43], and the electron transfer reaction on nitinol were monitored [9,44], whereas the release of $\mathrm{Ni}^{2+}$ ions from NiTi/Steel joints was visualized using alternating current scanning electrochemical microscopy (AC-SECM) [45,46]. In all the reported investigations, the impact of anodic polarization and the eventual breakdown of the passive layer on nitinol were investigated while this metallic material was polarized. Thus, transferring the cathodic process from the surface of the alloy to an auxiliary electrode placed inside the electrochemical cell. However, to the best of our knowledge, the SECM has not been employed to visualize the anodic and cathodic sites developed on the corroding nitinol surface, as well as to identify the chemical reactions at those places as a result of the surface modification produced during the application of a temporary anodic polarization. Although the oxide layer formed on titanium is known to repair from eventual breakdown for anodic polarizations even higher than those experienced in the human body [9,47], the eventual self-healing ability of nitinol has not been ascertained accordingly.

In this work we report the in situ electrochemical characterizations of nitinol, before and after anodic polarization experiments, by means of SECM operated using a versatile combination of amperometric and potentiometric operation modes.

\section{Experimental}

\subsection{Materials}

Nitinol wire with $0.8 \mathrm{~mm}$ diameter and $2 \mathrm{~cm}$ length was supplied by Goodfellow (Cambridge, UK). It was embedded vertically into epoxy resin (Struers, Ballerup, Denmark) using a cylindrical mold. The upper surface of the resulting cylinder was abraded to expose the nitinol surface exposed on the planar base. The upside face of the sample was the actual surface to be investigated. Prior to each experiment, the sample was abraded with silicon carbide paper down to 4000 grit, and subsequently polished using alumina slurries (diameter of $1,0.2$, and $0.05 \mu \mathrm{m})$.

The electrochemical cell was built by wrapping cellulose tape around the cylindrical plastic body creating a cell with an internal volume of $4 \mathrm{~mL}$. The experiments were performed in naturally aerated $0.1 \mathrm{M} \mathrm{NaCl}$ (Sigma-Aldrich, St. Louis, MO, USA) as test electrolyte 
(initial pH, 6.6). In selected SECM experiments, ferrocene-methanol (FcMeOH; Aldrich) was added to the test electrolyte to serve as an electrochemical redox mediator.

\subsection{Methods}

Energy dispersive X-ray spectroscopy (EDX, Ametek, USA) was employed to characterize the chemical composition of the nitinol surface. Figure 1A illustrates the EDX spectrum obtained by scanning an arbitrarily selected nitinol area of $250 \mu \mathrm{m} \times 250 \mu \mathrm{m}$. Titanium, nickel, and oxygen were detected with 43.43, 48.38 and 8.48 wt.\% ratios, respectively. The elemental distribution on the nitinol surface is shown in Figures $1 \mathrm{~B}, \mathrm{C}$ and D. The occurrence of oxygen is due to the surface oxide layer present on the metallic material. Mostly the nitinol surface is covered by $\mathrm{NiO}$ and $\mathrm{TiO}_{2}$ as proved by the XPS reported in [8].

Electrochemical characterization of nitinol in the test environment using averaging electrochemical techniques was performed using a CHI604E type electrochemical workstation build by $\mathrm{CH}$ Instruments (Houston, TX, USA). Before each experiment, the target was abraded with silicon carbide paper down to 4000 grit, and subsequently polished with a sequence of alumina slurries (diameter of $1,0.2$, and $0.05 \mu \mathrm{m}$ ). Afterwards, the sample was kept dry at room temperature. All the experiments were done at ambient temperature. The embedded nitinol sample was connected as the working electrode, and the 3-electrode configuration was attained with $\mathrm{Ag} / \mathrm{AgCl} /(3 \mathrm{M}) \mathrm{KCl}$ reference and platinum auxiliary electrodes. The experiments were performed in naturally aerated $0.1 \mathrm{M} \mathrm{NaCl}$ (Sigma-Aldrich) as test electrolyte, which exhibited a pH of 6.6.

The SECM experiments were performed with a Uniscan model 370 SECM (BioLogic, Seyssinet-Pariset, France) using a PG580R bipotentiostat (Biologic, Seyssinet-Pariset, France) as electrochemical interface. Amperometric operation was ensured with an $\mathrm{Ag} / \mathrm{AgCl} /(3 \mathrm{M})$ $\mathrm{KCl}$ reference electrode, a platinum counter electrode, and a platinum disk of $15 \mu \mathrm{m}$ diameter and RG value of 10 as primary working electrode. For the application of a controlled anodic polarization to the nitinol sample, the second working electrode connection was employed. Unless otherwise indicated, all potential values given here are reported to the $\mathrm{Ag} / \mathrm{AgCl} /(3 \mathrm{M})$ $\mathrm{KCl}$ reference electrode. Potentiometric operation was accomplished using an antimony microelectrode fabricated from high purity antimony powder (Aldrich, St. Louis, MO, USA) according to the procedure reported in [48]. Calibration of the $\mathrm{pH}$-sensitive $\mathrm{Sb} / \mathrm{Sb}_{2} \mathrm{O}_{3}$ microelectrode was carried out in a series of Britton-Robinson buffers in the $4 \leq \mathrm{pH} \leq 10$ range. The $\mathrm{pH}$ of the Britton-Robinson buffers was checked with a conventional $\mathrm{pH}$-meter 
using a combined glass $\mathrm{pH}$ electrode. Figure 2 shows a linear behavior with the slope of $-50.65 \mathrm{mV}$ decade ${ }^{-1}$ in good agreement with previous reports $[48,49]$.

\section{Results and discussion}

Electrochemical characterization of nitinol in the test environment was first performed using averaging electrochemical techniques. The potentiodynamic polarization measurement was recorded on a nitinol sample that was exposed to $0.1 \mathrm{M} \mathrm{NaCl}$ solution for $1.5 \mathrm{~h}$, and the recorded curve is shown in Figure 3. Inspection of the polarization curve allows to establish that the passivity range of nitinol in this environment extended up to $0.49 \mathrm{~V}$ vs. $\mathrm{Ag} / \mathrm{AgCl} /(3$ M) $\mathrm{KCl}$ from the observation of a passivation plateau in the current-potential curve. This feature supports that a rather stable passive oxide layer was formed on the nitinol surface. Nevertheless, when the potential scan reaches more positive potential values, an abrupt current increase occurred at $0.50 \mathrm{~V}$ vs. $\mathrm{Ag} / \mathrm{AgCl} /(3 \mathrm{M}) \mathrm{KCl}$, in good agreement with previous reports [13]. This means that over this potential the integrity of the passive oxide film fails leading to the initiation of localized pitting corrosion, as proved by the cyclic polarization results reported in ref. [9], where the observation of a positive hysteresis loop in the plot evidenced the susceptibility of nitinol to pitting corrosion.

Electrochemical impedance spectroscopy (EIS) measurements were performed in order to characterize the surface layers formed on the surface of a nitinol surface immersed in $0.1 \mathrm{M} \mathrm{NaCl}$ solution, either spontaneously at its corresponding open circuit potential, or as result of an anodic polarization procedure. Firstly, EIS data were recorded on the unbiased nitinol after $1.5 \mathrm{~h}$ exposure to the aerated test solution. Subsequently, nitinol was anodically polarized at $1.00 \mathrm{~V}$ vs. $\mathrm{Ag} / \mathrm{AgCl} /(3 \mathrm{M}) \mathrm{KCl}$ for $15 \mathrm{~min}$, and then the electrochemical impedance spectra was recorded on the biased material. The amplitude of the sinusoidal voltage perturbation was $10 \mathrm{mV}$ in the frequency range extending from $100 \mathrm{kHz}$ to100 mHz. The measured spectra are shown in Figure 4, displayed in the form of Bode diagrams. From the comparison of the two spectra (namely before and after anodic polarization at $1.00 \mathrm{~V}$ vs. $\mathrm{Ag} / \mathrm{AgCl} /(3 \mathrm{M}) \mathrm{KCl})$, it is clear that the electrochemical characteristics of the nitinol surface considerably changed due to anodic polarization.

The Bode diagrams of the unbiased material displayed two overlapping time constants, one at higher frequencies and the other in the low frequency range. At the high-frequency range, the bode modulus plot shows a narrow frequency interval constant $\log |Z|$ with a phase 
angle close to $0^{\circ}$ due to the electrolyte resistance developed between the reference electrode and the testing sample, similarly to what it is observed in the impedance spectrum of the anodically polarized nitinol. At intermediate frequencies, the Bode diagram related to unbiased nitinol presents a linear region with slope ca. -1 and a phase angle about $80^{\circ}$, which are characteristic features of a capacitive behaviour by the passive films [50,51]. It implies that nickel and titanium passive oxides were spontaneously formed over the nitinol surface upon immersion in the test electrolyte.

In a new series of experiments, the nitinol sample was anodically polarized at $+1.00 \mathrm{~V}$ for 15 min while immersed in the test electrolyte. This anodic potential value was selected as to be slightly more positive than the highest anodic polarization recorded in the human body until now [16]. After the anodic polarization was ceased, and ensuing a stable open circuit potential value was attained, electrochemical impedance spectra were recorded using the same experimental parameters than for recording the EIS data prior to polarization. In this case, the Bode diagrams recorded after the nitinol sample was,of anodically-biased nitinol showed twotime constants, clearly manifested by the observation of two well-separated peaks in the Bode-phase plot, one occurring in the frequency range $4 \geq \log f \geq 1.5 \mathrm{~Hz}$, while the other peak showed up between $1.5 \geq \log f \geq-1 \mathrm{~Hz}$. In this case, no region of linear behaviour could be observed in the $\log |Z|$ vs. $\log f$ plot at intermediate frequencies. This behavior could be the result of either a bilayer oxide structure [52,53], or the case of localized corrosion occurring on the metal surface $[54,55]$. Since the nitinol sample was polarized at $+1.00 \mathrm{~V}$, a potential value well beyond the passive region observed in the potentiodynamic polarization curve of Figure 3, the impedance spectrum describes the breakdown of the oxide film on the nitinol surface

In the sake to model the corrosion processes at the nitinol/electrolyte interface, two equivalent electric circuits (EEC) were proposed based on the above results, as shown in Figure 5. As it can be seen, a very good correlation was obtained between the simulated data and the experimental impedance spectra. The Bode diagram of unbiased nitinol was simulated using the EEC shown in Figure 5A. Composed by the electrolyte resistance $R_{\text {sol }}$ in series with two parallel RQ elements. The high frequency, $R_{\mathrm{ct}}$ and $Q_{\mathrm{dl}}$ describe the properties of the reactions at nitinol passive oxide/electrolyte interface, respectively the charge transfer resistance and the double layer capacitance [56]. Whereas, at low frequency, $R_{\mathrm{ox}}$ and $Q_{\mathrm{ox}}$ define the properties of the passive nitinol oxide layer correspondingly to, the resistance and capacitance of the barrier native oxide film [56]. The barrier characteristics of the oxide film 
formed on nitinol accounts for the high corrosion resistance of the material as it hindered the release of the hazardous metal cations to the electrolyte [43].

The EEC displayed in Figure 5B was employed to simulate the Bode diagrams of nitinol after anodic polarization at $+1.00 \mathrm{~V}$ for $15 \mathrm{~min}$. It was considered the most adequate circuit to analyze the electrochemical heterogeneity and the localized corrosion of the material. The first-time constant observed at high frequencies was composed by the electrolyte resistance in the pores of the oxide film $\left(R_{\mathrm{po}}\right)$ and the capacitance of the passivated area (intact) $Q_{\text {ox. }}$ On the other hand, the second time constant -observed at lower frequency values- takes into account the corrosion reaction at the nitinol substrate, characterized by the charge transfer resistance $\left(R_{\mathrm{ct}}\right)$ and the electrical double layer capacitance $\left(Q_{\mathrm{dl}}\right)$ inside the pores developed through the passive film [54,55].

Secondly, he electrochemical reactivity of the nitinol surface, before and after the application of anodic polarization, was investigated using SECM. In these experiments, the technique was first operated in the feedback mode employing a $15 \mu \mathrm{m}$ diameter platinum microelectrode as SECM probe. Ferrocene-methanol (FcMeOH) was added to the $0.1 \mathrm{M} \mathrm{NaCl}$ test electrolyte as reversible electrochemical mediator, and the platinum probe was polarized at $+0.60 \mathrm{~V}$ to monitor the current arising from the oxidation of FcMeOH [57]. 2D-mapping of the nitinol surface was performed using the meander pattern for data collection with a scan rate of $20 \mu \mathrm{m} \mathrm{s}^{-1}$. The tip-sample distance was set to $10 \mu \mathrm{m}$ after recording a $Z$-approach curve above the insulating resin in the proximity of the nitinol sample. Fitting the measured negative feedback plot to theoretical one helped to determine distance and to set the needed $10 \mu \mathrm{m}$ value. Subsequently, the probe moved in an $X Y$ plane parallel to the sample.

SECM mapping of unbiased nitinol recorded a homogenous current distribution all over the system, thus effectively producing the same response above the nitinol sample and the surrounding resin (namely $1.8 \mathrm{nA}$; the corresponding SECM map is shown as Figure 6). This feature implies that the scanned surface exhibited negative feedback character corresponding to a non-reactive surface towards electron transfer, effectively acting as an insulator towards the regeneration of the redox mediator. The close vicinity of the sample surface hindered the diffusion of the mediator to the measuring tip resulting in smaller current at the tip that in the bulk of the electrolyte (i.e., negative feedback response [58]). Therefore, besides the insulating characteristics of the resin, the passive oxide layer grown at the NiTi surface must be acting as a barrier film for the metal. This feature is in good agreement with the data supplied by conventional electrochemical characterization using EIS (cf. Figure 4). In addition, the surface must exhibit a high level of chemical homogeneity when immersed in the 
test electrolyte at its OCP, a feature that was supported by the ex situ characterization of the retrieved samples using scanning electron microscopy combined with energy dispersive X-ray analysis (SEM-EDS; see Figure 1). As result, the close vicinity of the sample surface to the scanning tip hinders the diffusion of the mediator to the Pt microelectrode resulting in the measurement of a smaller faradaic current than in the bulk of the electrolyte, a fact that is characteristic for a negative feedback mechanism [31].

The effect of anodic polarization on the passive state of nitinol immersed in the test electrolyte was investigated by applying a constant potential of $+1.00 \mathrm{~V}$ for $15 \mathrm{~min}$. The potential value was selected as to be slightly more positive than the highest anodic polarization recorded in the human body [16], and this value has often been selected as a potential safety threshold value for the in vitro testing of metallic biomaterials [32,33,53,36,59]. Unlike other titanium alloys, for which this anodic polarization value is well below the onset of pitting potential in simulated physiological solutions, passivity breakdown of the oxide layer formed on nitinol occurs at potential values negative to $+1.00 \mathrm{~V}$ [9] (cf. the potentiodynamic polarization plot given in Figure 3). In fact, the electrochemical impedance spectroscopy characterization of a nitinol sample after the anodic polarization at $+1.00 \mathrm{~V}$ was ceased, showed that the metal surface behaved as a complex electrochemical system where oxide covered and bare metal areas coexisted on the same material (see Figure 4).

SECM imaging in the feedback mode was performed above the nitinol sample after the anodic polarization at $+1.00 \mathrm{~V}$ was finished after $15 \mathrm{~min}$. A very chemicallyheterogeneous surface was found as shown in Figure 7A. In this case, tip currents greater than $1.8 \mathrm{nA}$ were recorded when the tip scanned locations close to the edges of the metal sample, whereas the tip currents measured above the remaining nitinol surface were eventually smaller than those recorded over the insulating resin. The heterogeneous distribution of the electrochemical activity over the metal surface towards the redox conversion of ferrocenemethanol is more easily observed from the inspection of the line scan depicted in Figure $7 \mathrm{~B}$ that shows a distribution of regions of different electrochemical activity as the tip moved from left to right. First, a current plateau was observed over the resin until the tip was moved to the nitinol surface, and this electrochemical response is characteristic for an insulator originating a negative feedback response. Next, an abrupt increase of the current recorded at the tip occurred over nitinol leading to the observation of a current peak of ca. $150 \mu \mathrm{m}$ width, subsequently followed by a region of small faradaic currents, effectively smaller than those previously recorded as the tip scanned over the resin. Further excursion of the tip led to the observation of another region of greater electrochemical activity that extended over a longer 
distance and led to the measurement of even higher tip currents. Finally, the current progressively decayed to values corresponding to the stationary negative feedback behavior occurring over the resin.

The occurrence of regions near the edges of the nitinol sample originating high tip currents in both the map and the line scan in Figure 7 must be explained in terms of the regeneration of the electrochemical mediator. That is, regions with greater surface conductivity resulted from the local breakdown of the barrier oxide layer naturally existing on nitinol during the polarization step at $+1.00 \mathrm{~V}$, and therefore electron exchange reactions involving redox species in the electrolytic phase can be sustained at them. The redox species to be considered are the ferrocene-methanol added as mediator to the electrolyte, and the oxidized species $\mathrm{FcMeOH}^{+}$that is formed at the tip polarized at $+0.60 \mathrm{~V}$. The electroreduction of $\mathrm{FcMeOH}^{+}$occurs at the cathodic sites formed on the actively corroding nitinol surface, thus effectively increasing the local concentration of the FcMeOH mediator that was found by the tip while scanning above them. This positive feedback effect is sketched in Figure $8[57,58]$. From the inspection of Figure 7 it is observed that cathodic sites were preferentially located near the edges of the nitinol sample, and they led to the measurement of faradaic tip currents significantly higher than those recorded over the surrounding resin. On the other hand, the local measurement of tip currents smaller than the values recorded over the surrounding resin can also be seen over certain areas of the sample surface (cf. Figure 7). This observation cannot be explained exclusively in terms of a negative feedback effect, because this would require the tip currents to match those recorded over the surrounding resin instead of even smaller values. An explanation for this feature could be provided by the eventual rebuilding of the passive oxide layer on the bare metal surface and its subsequent thickening $[60,61]$, because they would produce a decrease in the tip-sample distance, and thus increase the geometric shielding to the diffusion transport of the redox mediator towards the tip. However, growth of the oxide film thickness in the micrometer scale cannot be expected for NiTi. In fact, the thickness of the oxide layers formed on surface of titanium and its alloys typically comprise a few nanometers, even if they were formed under anodic polarization procedures [11]. Accordingly, any eventual change in thickness cannot noticeably affect the tip current when compared to the $10 \mu \mathrm{m}$ tip-sample gap. On the contrary, the occurrence of a redox-competition between the sample and the tip can provide a reasonable explanation for the observation of otherwise unexpected small current over certain areas of the investigated sample. The formation of active sites on the sample surface due to anodic polarization will lead to the development of areas with a local electric potential high 
enough to oxidize the FcMeOH mediator (see the process sketched in Figure 8). Then, the concentration of the reduced species of the redox mediator will be smaller in the regions close to the center of the sample due to competition with the tip for the same species, whereas this effect will be compensated by the increased transport of the mediator due to the spherical diffusion regime at regions closer to the sample boundaries, thus effectively reducing the impact of the redox competition mechanism. In fact, the redox competition mode of SECM has been reported to operate for various spontaneously corroding systems [29,30], even when redox mediators were not added into the environment [62-64].

Therefore, the polarization of nitinol at $+1.00 \mathrm{~V}$, even for a short time (namely 15 min), compromised the integrity of the passive surface layer leading to its localized breakdown, and the previously homogenous nitinol surface developed regions of different electrochemical activity. As result, certain localized regions were imaged by SECM displaying a redox competition behavior and they can be assigned to anodic sites developed on the surface that was mostly located at the center of the nitinol sample. On the other hand, positive feedback behavior was observed at the edges of the nitinol sample, as displayed in Figure 7, due to the development of cathodic sites. Hence, the most likely corrosion processes occurring in the actively corroding nitinol system following an anodic polarization stage can be described using a set of chemical reactions. At the anodic sites, the ionic release of the metals, mostly as $\mathrm{Ti}^{4+}$ and $\mathrm{Ni}^{2+}$ ions, occurs through reactions (1) and (2).

$$
\begin{aligned}
& \mathrm{Ti} \rightleftharpoons \mathrm{Ti}^{4+}+4 \mathrm{e}^{-} \\
& \mathrm{Ni} \rightleftharpoons \mathrm{Ni}^{2+}+2 \mathrm{e}^{-}
\end{aligned}
$$

The release of $\mathrm{Ti}^{4+}$ and $\mathrm{Ni}^{2+}$ ions from a nitinol sample soaked in $0.1 \mathrm{M} \mathrm{NaCl}$ solution acidified to $\mathrm{pH}=3.0$ was documented using atomic absorption spectroscopy $[10,25]$. Although local acidification at the anodic sites in the neutral $0.1 \mathrm{M} \mathrm{NaCl}$ cannot be expected to reach $\mathrm{pH}$ values as low as 3 (vide infra), the formation of these species can be regarded feasible at this stage. On the other hand, the cathodic reactions consuming the electrons liberated in the anodic sites should be either the hydrolysis of water or the reduction of dissolved oxygen [65]:

$$
\begin{aligned}
& \mathrm{H}_{2} \mathrm{O}+2 \mathrm{e}^{-} \rightleftharpoons 2 \mathrm{OH}^{-}+\uparrow \mathrm{H}_{2} \\
& \mathrm{O}_{2}+2 \mathrm{H}_{2} \mathrm{O}+4 \mathrm{e}^{-} \rightleftharpoons 4 \mathrm{OH}^{-}
\end{aligned}
$$

Hydrogen evolution monitoring over actively corroding nitinol as described by reaction (3) can be performed using SECM. In this case, the platinum microprobe is polarized 
at $0.00 \mathrm{~V}$ for the amperometric detection of hydrogen gas, and the SECM is effectively operated in the substrate generation-tip collection (SG/TC) mode [58]. This procedure has been successfully employed to monitor hydrogen evolving from corroding iron- and magnesium-based materials [66-71], although it has not been employed for the characterization of titanium and its alloys until now. In a new set of experiments, local hydrogen concentration was mapped over the nitinol sample immersed in $0.1 \mathrm{M} \mathrm{NaCl}$ solution after cessation of anodic polarization at $+1.00 \mathrm{~V}$ for $15 \mathrm{~min}$. The tip sample-distance was determined by setting the potential of the $15 \mu \mathrm{m}$ platinum probe set to $-0.60 \mathrm{~V}$ to monitor the oxygen reduction reaction. The precise positioning of the Pt tip with regards to the sample was accomplished by recording a $Z$-approach curve over the insulating resin surrounding the nitinol sample in order to monitor the negative feedback behavior of an electrical insulator. Next, the tip was retrieved to $10 \mu \mathrm{m}$ vertical distance from the surface, and the tip was moved parallel to the surface across the surface of nitinol while it was biased at $0.0 \mathrm{~V}$ for the detection of hydrogen gas evolving from the metal. The corresponding SECM map is shown in Figure 9A. Although a very small stationary tip current was measured while scanning over the epoxy resin, heterogeneously distributed high current values were detected over extensive regions of the samples near the edges, with the current maximum amounting to $96 \mathrm{pA}$. This feature evidences the evolution of hydrogen according to reaction (3). Furthermore, this finding strongly correlates with the observations raised from the experiments using the feedback mode that revealed the development of cathodic areas close to the edges of the nitinol sample as a result of previous anodic polarization. The various electrochemical activities observed on the nitinol surface using the SG/TC mode of SECM are sketched in Figure 9B.

In addition, the $\mathrm{pH}$ distributions developed in the solution adjacent to the corroding nitinol surface were monitored by SECM operated in the potentiometric mode using an antimony microelectrode tip as $\mathrm{pH}$-sensitive probe [49]. Prior to potentiometric operation, precise determination of the tip-sample distance was achieved from the $Z$-approach curve recorded above the surrounding resin while the antimony tip was polarized at $-0.60 \mathrm{~V}$ for the reduction of dissolved oxygen in the electrolyte. Next, the tip was retrieved a controlled distance from the sample into the liquid phase to form the $\mathrm{pH}$-sensitive oxide layer on the antimony tip under potentiostatic control. Finally, the tip-sample distance was set at $20 \mu \mathrm{m}$ for SECM imaging to record a $4000 \mu \mathrm{m}$ long line scan over the nitinol sample exposed to $0.1 \mathrm{M}$ $\mathrm{NaCl}$ solution following an anodic polarization step at $+1.00 \mathrm{~V}$ for $15 \mathrm{~min}$. In recording the $\mathrm{pH}$ - distance line scan along the $X$ axis, the $\mathrm{Sb}_{2} \mathrm{Sb}_{2} \mathrm{O}_{3}$ microelectrode probe crossed 
approximately above the center of the nitinol sample, whereas the potential of the tip with respect to the $\mathrm{Ag} / \mathrm{AgCl} /(3 \mathrm{M}) \mathrm{KCl}$ reference electrode was monitored at each point. Using the calibration curve, the potentials sensed at the tip could be transformed into local $\mathrm{pH}$ values as shown in Figure 10. When the probe was moved above the insulating resin, the recorded $\mathrm{pH}$ values closely matched those in the bulk of the solution, namely, $\mathrm{pH}=6.5$. Conversely, acidification of the electrolyte adjacent to the nitinol surface was found when the probe traveled over the nitinol surface, although distributed in a heterogeneous way. Thus, the lowest $\mathrm{pH}$ value of 5.6 was observed on the nitinol surface at locations close to the metal edge on the left side, and this acidification occurred very abruptly following an initial although small alkalization very close to the edge of the sample, which is more clearly observable in the inset of Figure 10. Further excursion of the tip to the right side was accompanied by a progressive rise of the $\mathrm{pH}$ reaching an almost stationary value around 6.1 over the majority of the sample. Finally, the $\mathrm{pH}$ values increased towards the values typical of the bulk electrolyte as the opposite edge of the metal sample was approached, as it could be expected from mass transport under diffusion conditions. The slight alkalization observed at the edge of the nitinol sample at the left must result from the reduction of water at a cathodic site according to reaction (3), whereas the subsequent acidification over most of the exposed metal surface can be explained considering the dissolution of metal cations from anodic areas. In corrosion mechanisms, the hydrolysis of the hydrated metal cations according to the general equation (5) must be taken into account [72]:

$$
\mathrm{M}^{n^{+}}+x \mathrm{H}_{2} \mathrm{O} \rightleftharpoons \mathrm{M}(\mathrm{OH})_{x}^{(n-x)+}+x \mathrm{H}^{+}
$$

So far, $\mathrm{Ni}^{2+}$ and $\mathrm{Ti}^{4+}$ were assumed to be the cations released from the actively corroding metal surface, although $\mathrm{Ni}(\mathrm{OH})_{2}$ and $\mathrm{Ti}(\mathrm{OH})_{4}$ are the more stable metal hydroxides [73,74]. By taking into account the solubility products, $K_{\mathrm{sp}}$, of $\mathrm{Ni}(\mathrm{OH})_{2}$ and $\mathrm{Ti}(\mathrm{OH})_{4}$ in aqueous solution (respectively, $5.7 \times 10^{-16}$ and $7.24 \times 10^{-30}[74,75]$ ), it should be considered that $\mathrm{Ni}^{2+}$ will be released preferentially from the corroding nitinol surface due to the very small solubility of Ti(IV) species. This feature has been confirmed in previous studies [24,25,76], including the localized detection of $\mathrm{Ni}^{2+}$ from activated NiTi using a stripping mode in SECM by Ruhlig et al. [46]. Therefore, the relatively large $\mathrm{pH}$ change produced over a rather small distance should originate from a high metal dissolution rate as the anodic and cathodic sites were located close to each other. Similar trends were previously observed for $\mathrm{Mg} / \mathrm{steel}$ galvanic couple [77]. 
Finally, the eventual reduction of dissolved oxygen at the cathodic sites developed on the corroding nitinol surface could not be investigated in this work using scanning electrochemical microscopy. Although this reaction is usually investigated by SECM in amperometric operation with the Pt tip polarized to a potential equal or slightly more negative than $-0.50 \mathrm{~V}$ [78], such measurement was not feasible this time due to the interference of both the eventual reduction of hydrogen ions [64], and the reduction of dissolved $\mathrm{Ni}(\mathrm{II})$ species (e.g., $\left.E_{N i}^{2} / \mathrm{Ni}=-0.25 \mathrm{VSHE},[75]\right)$.

\section{Conclusion}

In this study, the electrochemical characterization of nitinol both before and after the application of an anodic treatment were investigated using a combination of operation modes in SECM. In this way, the corrosion processes accounting for the degradation of nitinol exposed to a saline solution as result of its electrochemical activation following anodic polarization were identified, and they are sketched in Figure 11.

Operation of the SECM in the amperometric mode evidenced that unbiased nitinol immersed in $0.1 \mathrm{M} \mathrm{NaCl}$ solution exhibits a homogeneous insulating surface character. The oxide layer naturally developed on the surface of the material hinders electron transfer reactions to occur with redox mediators present in the aqueous phase. Conversely, an electrochemically heterogeneous surface results after the application of an anodic polarization treatment to nitinol, due to passive layer breakdown and the onset of active corrosion reactions. A heterogeneous distribution of anodic and cathodic reaction sites is observed to develop extending over different active areas on the surface of the material.

By operating the SECM in the SG/TC mode, the evolution of hydrogen gas from the cathodic sites was demonstrated. In addition, $\mathrm{pH}$ distribution in the adjacent electrolyte was also mapped using SECM in the potentiometric mode. Local acidification was detected around the anodic spots accompanying the release of $\mathrm{Ni}^{2+}$ ionic species, whereas alkalization occurred next to the cathodic sites due to the release of hydroxide ions.

As result, it has been demonstrated that nitinol exhibits feeble corrosion resistance after undergoing an oxidative anodic polarization stage at potential values that can be encountered in the human body. These findings, considered as a new contribution towards the mechanistic characterization of nitinol corrosion through the visualization of the anodic and cathodic areas and the identification of the corrosion reactions occurring in the active sites, 
are regarded to have a high interest regarding the potential use of nitinol as biomaterial for implantation due to the harmful health effects of nickel.

\section{Acknowledgements}

The work was supported by the Hungarian Research Grant NFKI Nr. 125244 (Budapest, Hungary), and by the Spanish Ministry of Economy and Competitiveness (MINECO, Madrid, Spain) and the European Regional Development Fund (Brussels, Belgium) under grant CTQ2016-80522-P. Abdelilah Asserghine expresses his gratitude to Stipendium Hungaricum program for support.

\section{References}

1. S. Shabalovskaya, J. Anderegg, J. Van Humbeeck, Critical overview of nitinol surfaces and their modifications for medical applications, Acta Biomater. 4 (2008) 447-467.

2. S. Shabalovskaya, Physicochemical and biological aspects of nitinol as a biomaterial, Int. Mater. Rev. 46 (2001) 233-250.

3. L.G. Machado, M.A. Savi, Medical applications of shape memory alloys, Braz. J. Med. Biol. Res. 36 (2003) 683-691.

4. T. Duerig, A. Pelton, D. Stöckel, An overview of nitinol medical applications, Mater. Sci. Eng. A 273 (1999) 149-160.

5. W.R. Proffit, H.W. Fields Jr., D.M. Sarver, Contemporary Orthodontics, $4^{\text {th }}$ Edition, Mosby Elsevier, St. Louis, MO, 2007. ISBN-13: 978-0-323-04046-4.

6. C. Veiga, J.P. Davim, A.J.R. Loureiro, Properties and applications of titanium alloys: a brief review, Rev. Adv. Mater. Sci. 32 (2012) 14-34.

7. P. Filip, J. Lausmaa, J. Musialek, K. Mazanec, Structure and surface of TiNi human implants, Biomaterials 22 (2001) 2131-2138.

8. I. Milošev, B. Kapun, The corrosion resistance of nitinol alloy in simulated physiological solutions: Part 2: The effect of surface treatment, Mater. Sci. Eng. C 32 (2012) 10681077.

9. J. Izquierdo, M.B. González-Marrero, M. Bozorg, B.M. Fernández-Pérez, H.C. Vasconcelos, J.J. Santana, R.M. Souto, Multiscale electrochemical analysis of the corrosion of titanium and nitinol for implant applications, Electrochim. Acta 203 (2016) 366-378. 
10. A. Asserghine, M. Medividović-Kosanović, L. Nagy, G. Nagy, In situ monitoring of the transpassivation and repassivation of the passive film on nitinol biomaterial by scanning electrochemical microscopy, Electrochem. Commun. 107 (2019) 106359, 6 pp.

11. A. Mazzarolo, M. Curioni, A. Vicenzo, P. Skeldon, G.E. Thompson, Anodic growth of titanium oxide: electrochemical behaviour and morphological evolution, Electrochim. Acta 75 (2012) 288-295.

12. N. Figueira, T.M. Silva, M.J. Carmezim, J.C.S. Fernandes, Corrosion behaviour of NiTi alloy, Electrochim. Acta 54 (2009) 921-926.

13. M. Mirjalili, M. Momeni, N. Ebrahimi, M.H. Moayed, Comparative study on corrosion behaviour of nitinol and stainless-steel orthodontic wires in simulated saliva solution in presence of fluoride ions, Mater. Sci. Eng. C 33 (2013) 2084-2093.

14. B.G. Pound, Susceptibility of nitinol to localized corrosion, J. Biomed. Mater. Res. A 77 (2006) 185-191.

15. M. Geetha, A.K. Singh, R. Asokamani, A.K. Gogia, Ti based biomaterials the ultimate choice for orthopaedic implants A review, Prog. Mater. Sci. 54 (2009) 397-425.

16. G. Rondelli, B.Vicentini, Effect of copper on the localized corrosion resistance of Ni-Ti shape memory alloy, Biomaterials 23 (2002) 639-644.

17. S. Shabalovskaya, Surface, corrosion and biocompatibility aspects of nitinol as an implant material, Biomed. Mater. Eng. 12 (2002) 69-109.

18. A. Wadood, Brief overview on nitinol as biomaterial, Adv. Mater. Sci. Eng. 4 (2016) 1-9.

19. S.J.L. Sullivan, D. Madamba, S. Sivan, K. Miyashiro, M.L. Dreher, C. Trépanier, S. Nagaraja, The effects of surface processing on in-vivo corrosion of Nitinol stents in a porcine model, Acta Biomater. 62 (2017) 385-396.

20. J. Géringer, K. Kim, Fretting corrosion in biomedical implants, in: Tribocorrosion of Passive Metals and Coatings, D. Landolt, S. Mischler, Eds.; Woodhead Publishing: Cambridge, UK, 2011, pp. 401-423. ISBN 978-1-84569-966-6.

21. J. Geringer, B. Forest, P. Combrade, Fretting-corrosion of materials used as orthopaedic implants, Wear 259 (2005) 943-951.

22. D.W. Hoeppner, V. Chandrasekaran, Fretting in orthopaedic implants: a review, Wear 173 (1994) 189-197.

23. E. Lukina, M. Kollerov, J. Meswania, A. Khon, P. Panin, G.W. Blunn, Fretting corrosion behavior of Nitinol spinal rods in conjunction with titanium pedicle screws, Mater. Sci. Eng. C 72 (2017) 601-610. 
24. D.J. Wever, A.G. Veldhuizen, J. de Vries, H.J. Busscher, D.R.A. Uges, J.R. van Horn, Electrochemical and surface characterization of a nickel-titanium alloy, Biomaterials 19 (1998) 761-769.

25. H.H. Huang, Y.H. Chiu, T.H. Lee, S.C. Wu, H.W. Yang, K.H. Su, C.C. Hsu, Ion release from NiTi orthodontic wires in artificial saliva with various acidities, Biomaterials 24 (2003) 3585-3592.

26. P.H. Gitlitz, F.W. Sunderman Jr., P.J. Goldblatt, Aminoaciduria and proteinuria in rats after a single intraperitoneal injection of Ni(II), Toxicol. Appl. Pharmacol. 34 (1975) 430-440.

27. M.C. Pereira, M.L. Pereira, J.P. Sousa, Evaluation of nickel toxicity on liver, spleen, and kidney of mice after administration of high-dose metal ion, J. Biomed. Mater. Res. 40 (1998) 40-47.

28. Nickel and nickel compounds, in: A review of human carcinogens. Volume $100 \mathrm{C}$ : Arsenic, Metals, Fibres, and Dusts, IARC Monographs, International Agency for Research on Cancer, Lyon (France), 2012, pp. 169-218. ISBN: 978-92-832-1320-8.

29. M.B. Jensen, D.E. Tallman, Application of SECM to corrosion studies, in: Electroanalytical Chemistry: A Series of Advances, Volume 24, A.J. Bard, C.G. Zoski, Eds.; CRC Press: Boca Raton, FL, 2012, pp. 171-286. ISBN 978-1-4398-3750-4.

30. N.A. Payne, L.I. Stephens, J. Mauzeroll, The application of scanning electrochemical microscopy to corrosion research, Corrosion 73 (2017) 759-780.

31. G. Ciurescu, J. Izquierdo, J.J. Santana, D. Mareci, D. Sutiman, S. González, R.M. Souto, Characterization of the localized surface chemical activity of Ti-Mo and Ti-Ta alloys for biomedical applications using scanning electrochemical microscopy, Int. J. Electrochem. Sci. 7 (2012) 7404-7424.

32. G. Bolat, D. Mareci, R. Chelariu, J. Izquierdo, S. González, R.M. Souto, Investigation of the electrochemical behaviour of TiMo alloys in simulated physiological solutions, Electrochim. Acta 113 (2013) 470-480.

33. R. Chelariu, G. Bolat, J. Izquierdo, D. Mareci, D.M. Gordin, T. Gloriant, R.M. Souto, Metastable beta Ti-Nb-Mo alloys with improved corrosion resistance in saline solution, Electrochim. Acta 137 (2014) 280-289.

34. J. Izquierdo, G. Bolat, D. Mareci, C. Munteanu, S. González, R.M. Souto, Electrochemical behaviour of ZrTi alloys in artificial physiological solution simulating in vitro inflammatory conditions, Appl. Surf. Sci. 313 (2014) 259-266. 
35. N. Casillas, S.J. Charlebois, W.H. Smyrl, H.S. White, Scanning electrochemical microscopy of precursor sites for pitting corrosion on titanium, J. Electrochem. Soc. 140 (1993) L142-L145.

36. N. Casillas, S. Charlebois, W.H. Smyrl, H.S. White, Pitting corrosion of titanium, J. Electrochem. Soc. 141 (1994) 636-642.

37. L.F. Garfias-Mesias, M. Alodan, P.I. James, W.H. Smyrl, Determination of precursor sites for pitting corrosion of polycrystalline titanium by using different techniques, $\mathrm{J}$. Electrochem. Soc. 145 (1998) 2005-2010.

38. S.E. Pust, D. Scharnweber, C.N. Kirchner, G. Wittstock, Heterogeneous distribution of reactivity on metallic biomaterials: scanning probe microscopy studies of the biphasic $\mathrm{Ti}$ alloy Ti6Al4V, Adv. Mater. 19 (2007) 878-882.

39. R. Zhu, C. Nowierski, Z. Ding, J.J. Noël, D.W. Shoesmith, Insights into grain structures and their reactivity on grade-2 Ti alloy surfaces by scanning electrochemical microscopy, Chem. Mater. 19 (2007) 2533-2543.

40. S.E. Pust, D. Scharnweber, S. Baunack, G. Wittstock, Electron transfer kinetics at oxide films on metallic biomaterials - Scanning electrochemical microscopy studies of Ti6Al4V, J. Electrochem. Soc. 154 (2007) C508-C514.

41. R. Zhu, Z. Qin, J.J. Noël, D.W. Shoesmith, Z. Ding, Analyzing the influence of alloying elements and impurities on the localized reactivity of titanium grade-7 by scanning electrochemical microscopy, Anal. Chem. 80 (2008) 1437-1447.

42. A. Asserghine, D. Filotás, L. Nagy, G. Nagy, Scanning electrochemical microscopy investigation of the rate of formation of a passivating $\mathrm{TiO}_{2}$ layer on a $\mathrm{Ti} \mathrm{G} 4$ dental implant, Electrochem. Commun. 83 (2017) 33-35.

43. A. Asserghine, D. Filotás, B. Németh, L. Nagy, G. Nagy, Potentiometric scanning electrochemical microscopy for monitoring the $\mathrm{pH}$ distribution during the self-healing of passive titanium dioxide layer on titanium dental root implant exposed to physiological buffered (PBS) medium, Electrochem. Commun. 95 (2018) 1-4.

44. A. Maho, F. Kanoufi, C. Combellas, J. Delhalle, Z. Mekhalif, Electrochemical investigation of nitinol/tantalum hybrid surfaces modified by alkylphosphonic selfassembled monolayers, Electrochim. Acta 116 (2014) 78-88.

45. A. Schulte, S. Belger, M. Etienne, W. Schuhmann, Imaging localised corrosion of NiTi shape memory alloys by means of alternating current scanning electrochemical microscopy (AC-SECM), Mater. Sci. Eng. A 378 (2004) 523-526. 
46. D. Ruhlig, H. Gugel, A. Schulte, W. Theisen, W. Schuhmann, Visualization of local electrochemical activity and local nickel ion release on laser-welded $\mathrm{NiTi} /$ steel joints using combined alternating current mode and stripping mode SECM, Analyst 133 (2008) 1700-1706.

47. G.T. Burstein, R.M. Souto, Observations of localised instability of passive titanium in chloride solution, Electrochim. Acta 40 (1995) 1881-1888.

48. B. Horrocks, M.V. Mirkin, D.T. Pierce, A.J. Bard, G. Nagy, K. Toth, Scanning electrochemical microscopy. 19. Ion-selective potentiometric microscopy, Anal. Chem. 65 (1993) 1213-1224.

49. J. Izquierdo, L. Nagy, Á. Varga, J.J. Santana, G. Nagy, R.M. Souto, Spatially resolved measurement of electrochemical activity and $\mathrm{pH}$ distributions in corrosion processes by scanning electrochemical microscopy using antimony microelectrode tips, Electrochim. Acta 56 (2011) 8846-8850.

50. J.E.G. González, J.C. Mirza-Rosca, Study of the corrosion behavior of titanium and some of its alloys for biomedical and dental implant applications, J. Electroanal. Chem. 471 (1999) 109-115.

51. B.L. Wang, Y.F. Zheng, L.C. Zhao, Effects of Hf content and immersion time on electrochemical behavior of biomedical $\mathrm{Ti}-22 \mathrm{Nb}-\mathrm{xHf}$ alloys in $0.9 \% \mathrm{NaCl}$ solution, Mater. Corros. 60 (2009) 330-335.

52. A.C. Alves, F. Wenger, P. Ponthiaux, J.P. Celis, A.M. Pinto, L.A. Rocha, J.C.S. Fernandes, Corrosion mechanisms in titanium oxide-based films produced by anodic treatment, Electrochim. Acta 234 (2017) 16-27.

53. G. Bolat, J. Izquierdo, J.J. Santana, D. Mareci, R.M. Souto, Electrochemical characterization of ZrTi alloys for biomedical applications, Electrochim. Acta 88 (2013) 447-456.

54. M. Alishahi, F. Mahboubi, S.M. MousaviKhoie, M. Aparicio, E. Lopez-Elvira, J. Mendez, R. Gago, Structural properties and corrosion resistance of tantalum nitride coatings produced by reactive DC magnetron sputtering, RSC Adv. 6 (2016) 8906189072.

55. A.P. Romano, M.G. Olivier, Investigation by electrochemical impedance spectroscopy of filiform corrosion of electrocoated steel substrates, Prog. Org. Coat. 89 (2015) 1-7.

56. G. Bolat, J. Izquierdo, D. Mareci, D. Sutiman, R.M. Souto, Electrochemical characterization of ZrTi alloys for biomedical applications. Part 2: The effect of thermal oxidation. Electrochim. Acta 106(2013) 432-439. 
57. D. Polcari, P. Dauphin-Ducharme, J. Mauzeroll, Scanning electrochemical microscopy: a comprehensive review of experimental parameters from 1989 to 2015, Chem. Rev. 116 (2016) 13234-13278.

58. A.J. Bard, Introduction and principles, in: Scanning Electrochemical Microscopy, Second Edition, A.J. Bard, M.V. Mirkin, Eds.; CRC Press: Boca Raton, FL, 2012, pp. 1-14. ISBN

59. L.C. Trincă, D. Mareci, C. Solcan, M. Fântânariu, L. Burtan, L Hriţcu, C. Chiruţă, L. Fernández-Mérida, R. Rodríguez-Raposo, J.J. Santana, R.M. Souto, New Ti-6Al-2Nb2Ta-1Mo alloy as implant biomaterial: in vitro corrosion and in vivo osseointegration evaluations, Mater. Chem. Phys. 240 (2020) 122229, 10 pp.

60. C. Wei, A.J. Bard, Scanning electrochemical microscopy XXIX. In situ monitoring of thickness changes of thin films on electrodes, J. Electrochem. Soc. 142 (1995) 25232527.

61. P. Dauphin-Ducharme, C. Kuss, D. Rossouw, N.A. Payne, L. Danis, G.A. Botton, J. Mauzeroll, Corrosion product formation monitored using the feedback mode of scanning electrochemical microscopy with carbon microelectrodes, J. Electrochem. Soc. 162 (2015) C677-C683.

62. R.M. Souto, L. Fernández-Mérida, S. González, SECM imaging of interfacial processes in defective organic coatings applied on metallic substrates using oxygen as redox mediator, Electroanalysis 21 (2009) 2640-2646.

63. J.J. Santana, J. González-Guzmán, L. Fernández-Mérida, S. González, R.M. Souto, Visualization of local degradation processes in coated metals by means of scanning electrochemical microscopy in the redox competition mode, Electrochim. Acta 55 (2010) 4488-4494.

64. S. Thomas, J. Izquierdo, N. Birbilis, R.M. Souto, Possibilities and limitations of scanning electrochemical microscopy of Mg and Mg alloys, Corrosion 71 (2015) 171-183.

65. V. Maurice, T. Nakamura, L.H. Klein, P. Marcus, Initial stages of localised corrosion by pitting of passivated nickel surfaces studied by scanning tunneling microscopy (STM) and atomic force microscopy (AFM), in: Local Probe Techniques for Corrosion Research, R. Oltra, V. Maurice, R. Akid, P. Marcus (Eds.), Woodhead Publishing, Cambridge, UK, 2007, pp. 71-83. ISBN-13: 978-1-84569-236-0.

66. K. Fushimi, K.A. Lill, H. Habazaki, Heterogeneous hydrogen evolution on corroding Fe3 at\% Si surface observed by scanning electrochemical microscopy, Electrochim. Acta 52 (2007) 4246-4253. 
67. U.M. Tefashe, M.E. Snowden, P.D. Ducharme, M. Danaie, G.A. Botton, J. Mauzeroll, Local flux of hydrogen from magnesium alloy corrosion investigated by scanning electrochemical microscopy, J. Electroanal. Chem. 720-721 (2014) 121-127.

68. S.S. Jamali, S.E. Moulton, D.E. Tallman, M. Forsyth, J. Weber, G.G. Wallace, Evaluating the corrosion behavior of magnesium alloy in simulated physiological fluid by using SECM to detect hydrogen evolution, Electrochim. Acta 152 (2015) 294-301.

69. S.H. Salleh, S. Thomas, J.A. Yuwono, K. Venkatesan, N. Birbilis, Enhanced hydrogen evolution on $\mathrm{Mg}(\mathrm{OH})_{2}$ covered Mg surfaces, Electrochim. Acta 161 (2015) 144-152.

70. J. Izquierdo, B.M. Fernández-Pérez, D. Filotás, Z. Öri, A. Kiss, R.T. Martín-Gómez, L. Nagy, G. Nagy, R.M. Souto, Imaging of concentration distributions and hydrogen evolution on corroding magnesium exposed to aqueous environments using scanning electrochemical microscopy, Electroanalysis 28 (2016) 2354-2366.

71. D. Filotás, B.M. Fernández-Pérez, L. Nagy, G. Nagy, R.M. Souto, A novel scanning electrochemical microscopy strategy for the investigation of anomalous hydrogen evolution from AZ63 magnesium alloy, Sens. Actuators B Chem. 308 (2020) 127691, 10 pp.

72. S.V. Lamaka, R.M. Souto, M.G.S. Ferreira, In situ visualization of local corrosion by scanning ion-selective electrode technique (SIET), in: Microscopy: Science, Technology, Applications and Education, vol. 3, A. Méndez-Vilas, J. Díaz (Eds.), Formatex Research Center, Badajoz (Spain), 2010, pp. 2162-2173.

73. M. Pourbaix, Atlas of Electrochemical Equilibria in Aqueous Solutions, Pergamon Press, Oxford, UK, 1966.

74. Y. Fovet, J.Y. Gal, F. Toumelin-Chemla, Influence of $\mathrm{pH}$ and fluoride concentration on titanium passivating layer: stability of titanium dioxide, Talanta 53 (2001) 1053-1063.

75. W.M. Haynes, D.R. Lide, T.J. Bruno (Eds.), CRC Handbook of Chemistry and Physics, 97 ${ }^{\text {th }}$ Edition, CRC Press, Boca Raton, FL, 2016, pp. 5-178.

76. M. Es-Souni, M. Es-Souni, H. Fischer-Brandies, Assessing the biocompatibility of NiTi shape memory alloys used for medical applications, Anal. Bioanal. Chem. 381 (2005) 557-567.

77. D. Trinh, P.D. Ducharme, U.M. Tefashe, J.R. Kish, J. Mauzeroll, Influence of edge effects on local corrosion rate of magnesium alloy/mild steel galvanic couple, Anal. Chem. 84 (2012) 9899-9906. 
78. A.C. Bastos, A.M. Simões, S. González, Y. González-García, R.M. Souto, Imaging concentration profiles of redox-active species in open-circuit corrosion processes with the scanning electrochemical microscope, Electrochem. Commun. 6 (2004) 1212-1215.

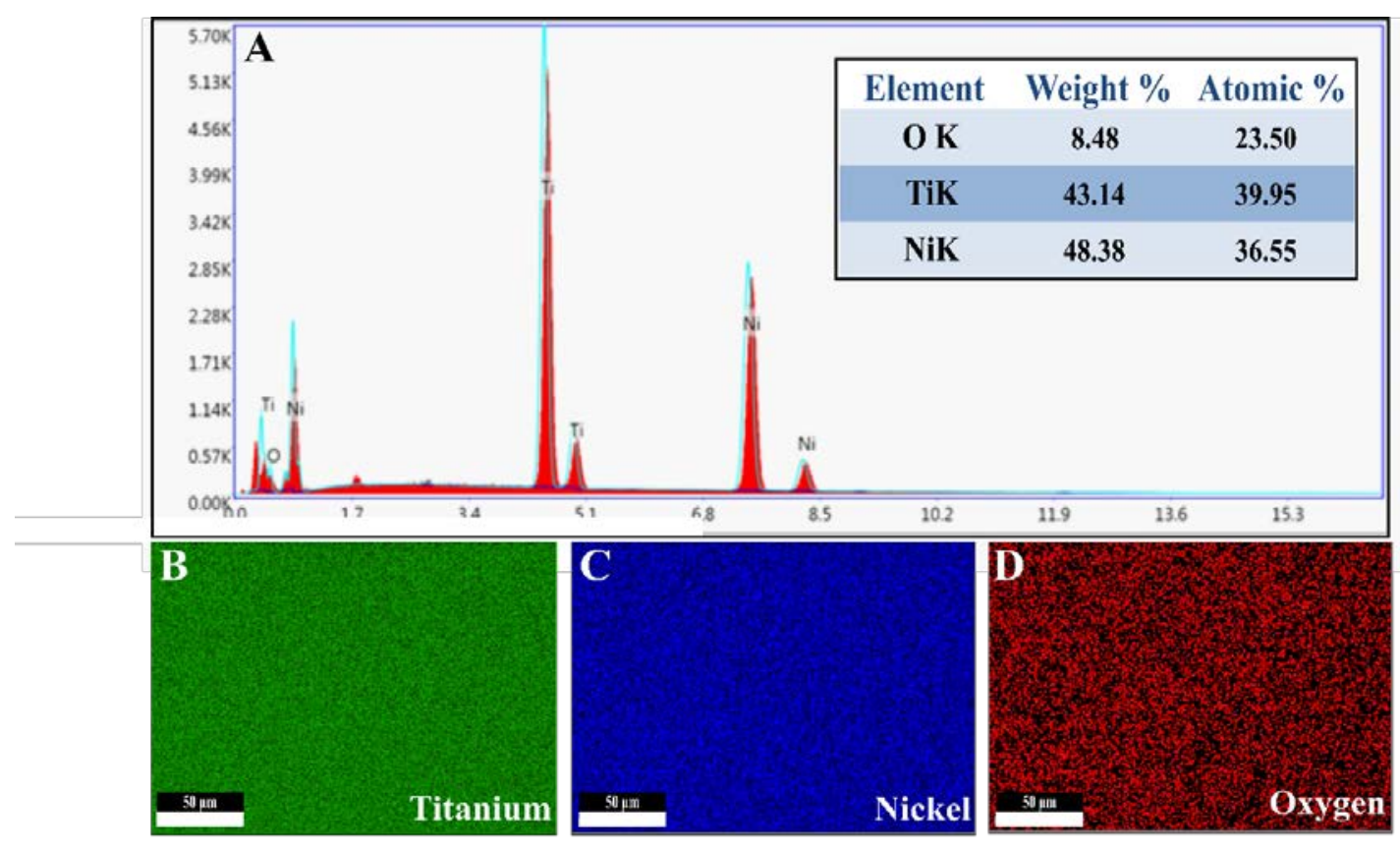

Figure 1

EDX analysis of the nitinol surface taken on an arbitrarily selected area of $250 \mu \mathrm{m} \times 250 \mu \mathrm{m}$. (A) EDX spectra, and elemental mapping of (B) titanium, (C) nickel, and (D) oxygen.

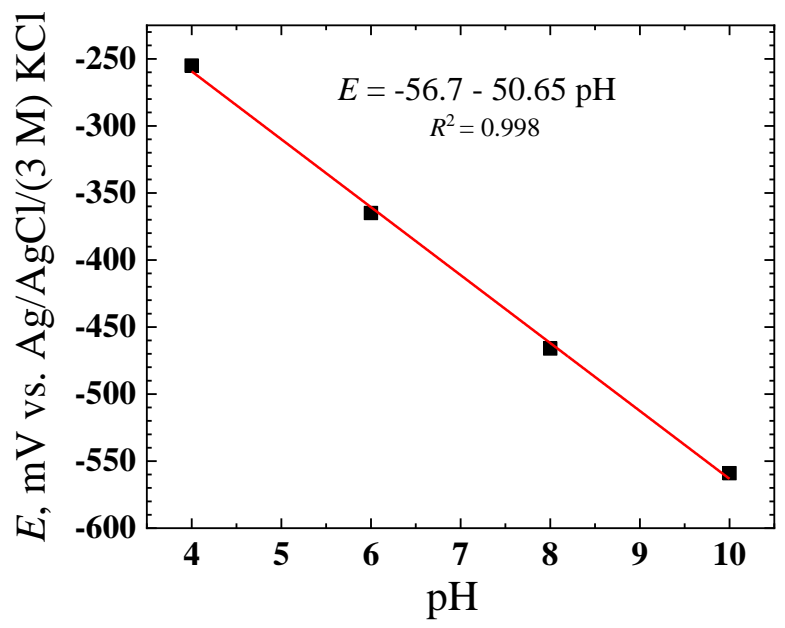

Figure 2

Calibration of the $\mathrm{Sb} / \mathrm{Sb}_{2} \mathrm{O}_{3}$ microelectrode. 


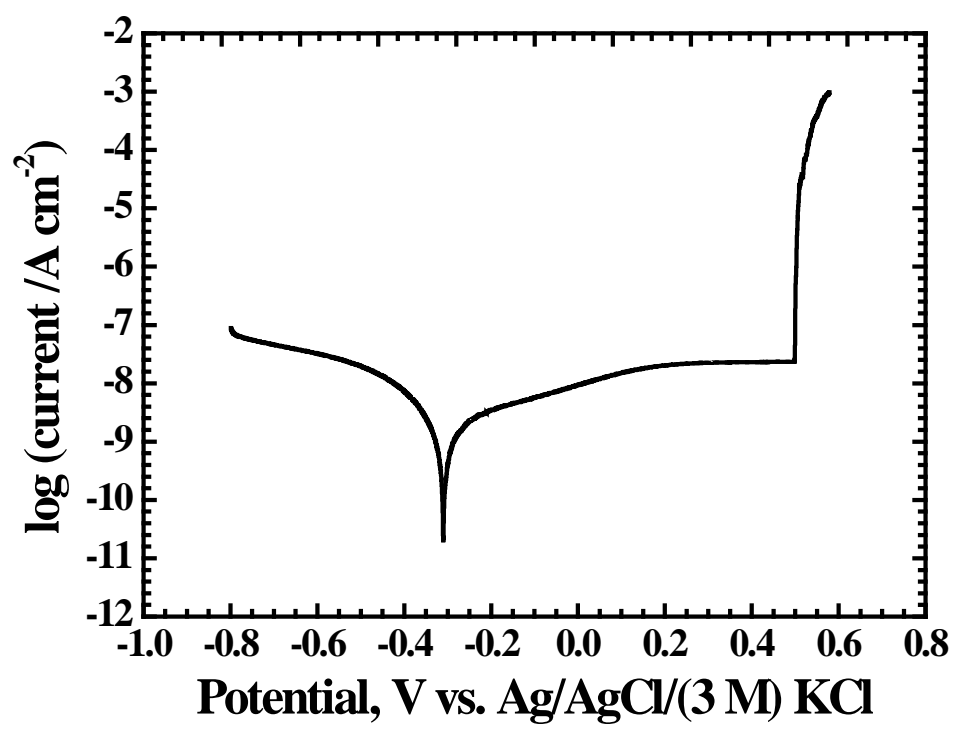

Figure 3

Potentiodynamic polarization curve recorded on nitinol immersed in $0.1 \mathrm{M} \mathrm{NaCl}$ solution for $90 \mathrm{~min}$. Scan rate: $1 \mathrm{mV} \mathrm{s}^{-1}$.

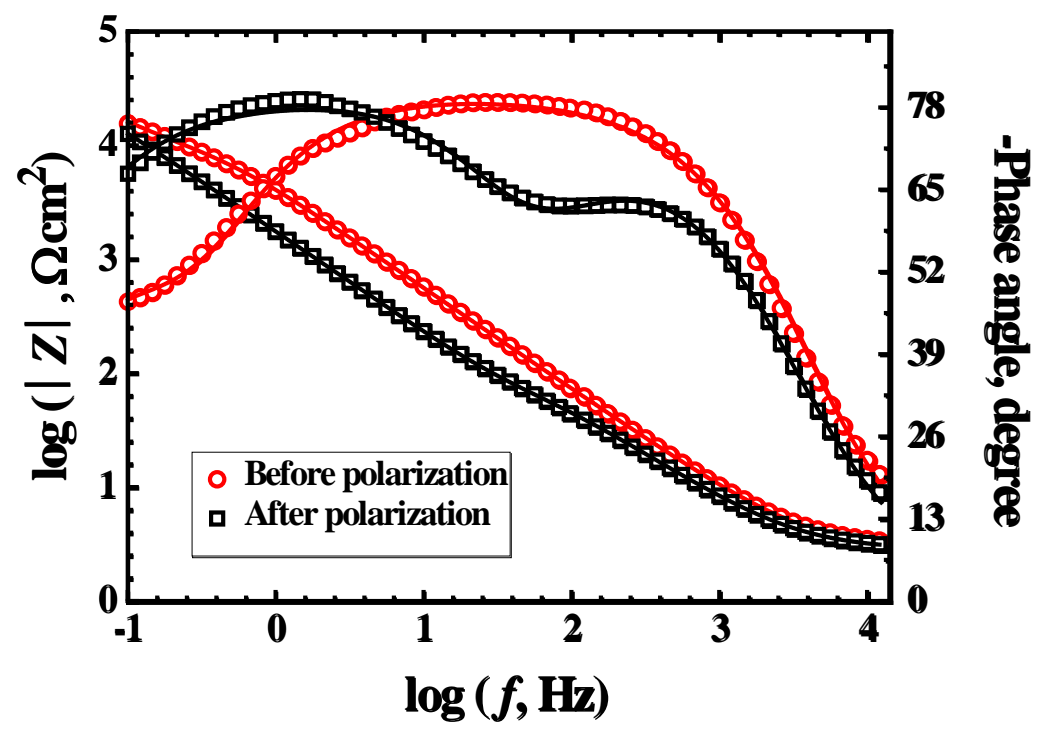

Figure 4

Bode plots recorded for nitinol immersed in $0.1 \mathrm{M} \mathrm{NaCl}$ solution for $90 \mathrm{~min}$ at different polarization conditions: (-O-) at the open circuit potential (before anodic polarization); and (- $\square-$ ) anodicallypolarized at $+1.00 \mathrm{~V}$ vs. $\mathrm{Ag} / \mathrm{AgCl} /(3 \mathrm{M}) \mathrm{KCl}$. 

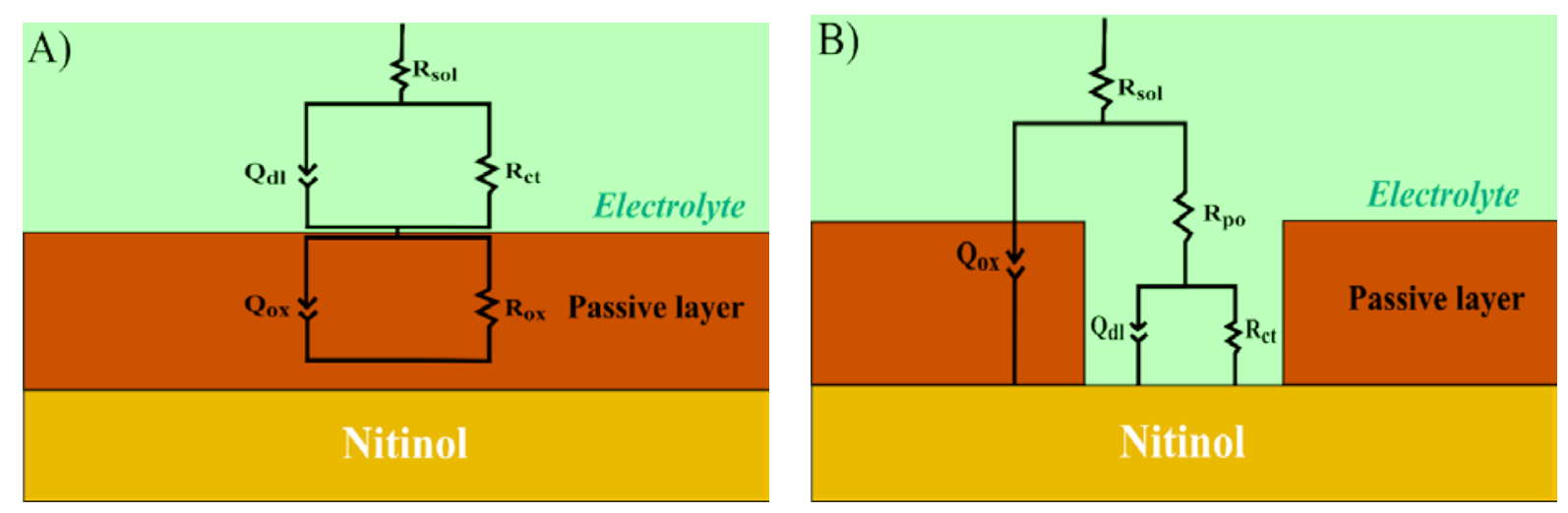

Figure 5

Equivalent electrical circuits (EEC) employed to simulate the impedance spectra recorded for nitinol immersed in $0.1 \mathrm{M} \mathrm{NaCl}$ solution for $90 \mathrm{~min}$ at different polarization conditions: (A) at the open circuit potential (before anodic polarization); and (B) anodically-polarized at $+1.00 \mathrm{~V}$ vs.

$$
\text { Ag/AgCl/(3 M) KCl. }
$$
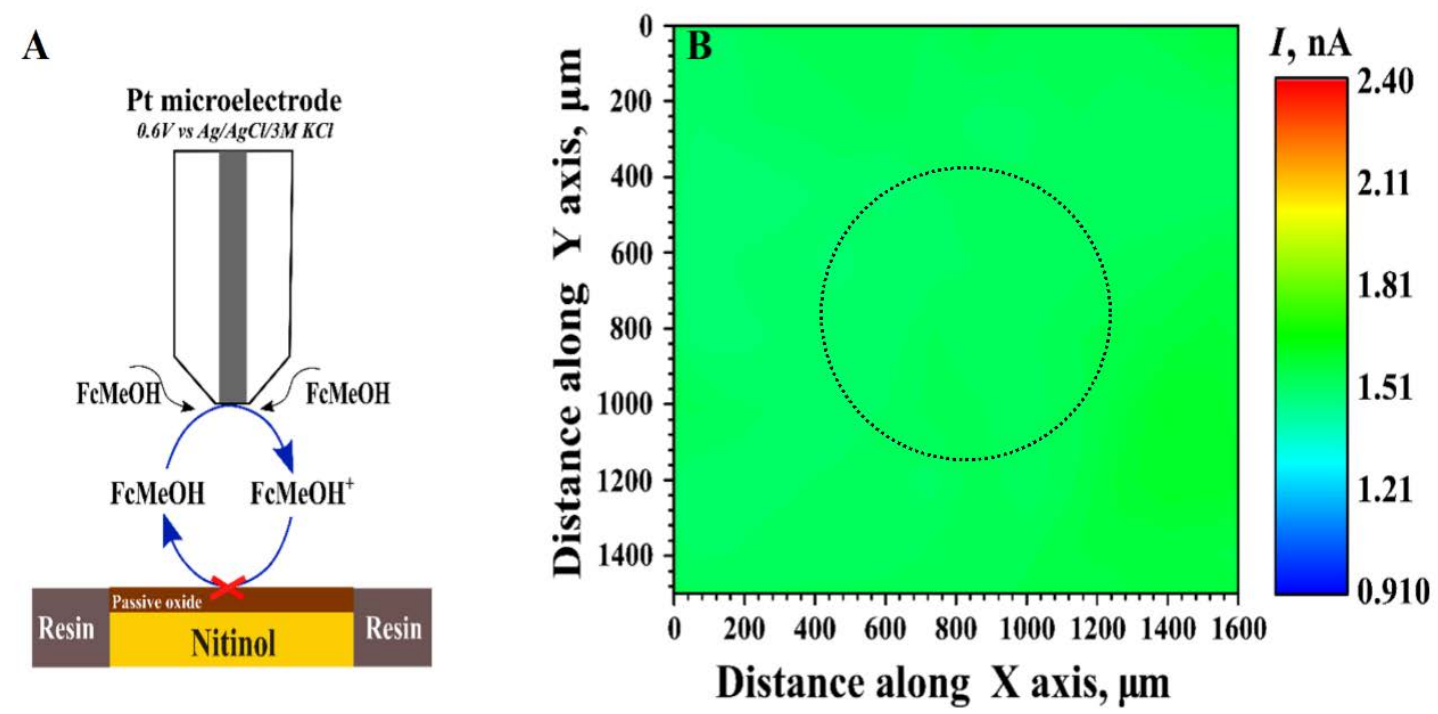

Figure 6

(A) Sketch of the negative feedback operation in SECM imaging. (B) SECM 2D-map of an unbiased nitinol sample immersed in $0.1 \mathrm{M} \mathrm{NaCl}+2 \mathrm{mM} \mathrm{FcMeOH}$ for 90 min. Tip diameter: $15 \mu \mathrm{m}$; tipsample distance: $10 \mu \mathrm{m}$; tip potential: $+0.60 \mathrm{~V} \mathrm{Ag} / \mathrm{AgCl} /(3 \mathrm{M}) \mathrm{KCl}$; scan rate: $20 \mu \mathrm{m} \mathrm{s}^{-1}$. 

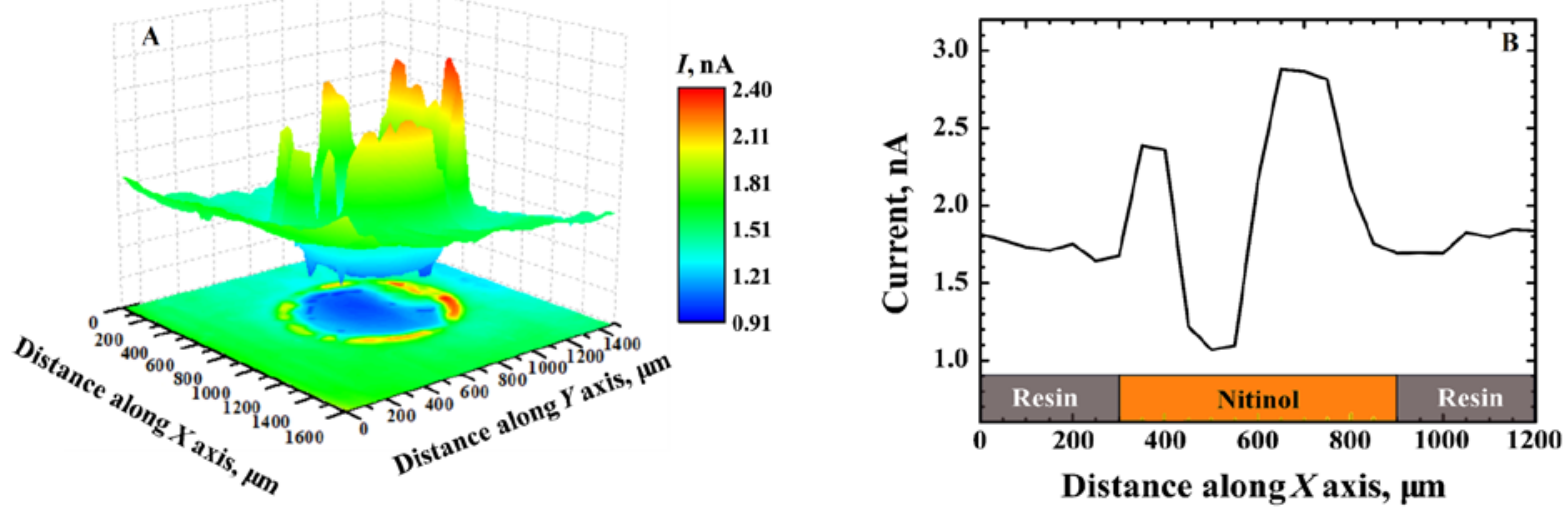

Figure 7

SECM imaging of a nitinol sample after polarization at $+1.00 \mathrm{~V}$ vs. Ag/AgCl/(3 M) KCl for $15 \mathrm{~min}$ during immersion in $0.1 \mathrm{M} \mathrm{NaCl}+2 \mathrm{mM}$ FcMeOH solution. (A) 2D scan (i.e., combined XY scanning); and (B) line scan recorded along the $X$ axis passing over the center of the metal sample in the $Y$ direction. Tip diameter: $15 \mu \mathrm{m}$; tip-sample distance: $10 \mu \mathrm{m}$; tip potential: $+0.60 \mathrm{~V} \mathrm{Ag/AgCl} /(3$

M) $\mathrm{KCl}$; scan rate: $20 \mu \mathrm{m} \mathrm{s}^{-1}$.

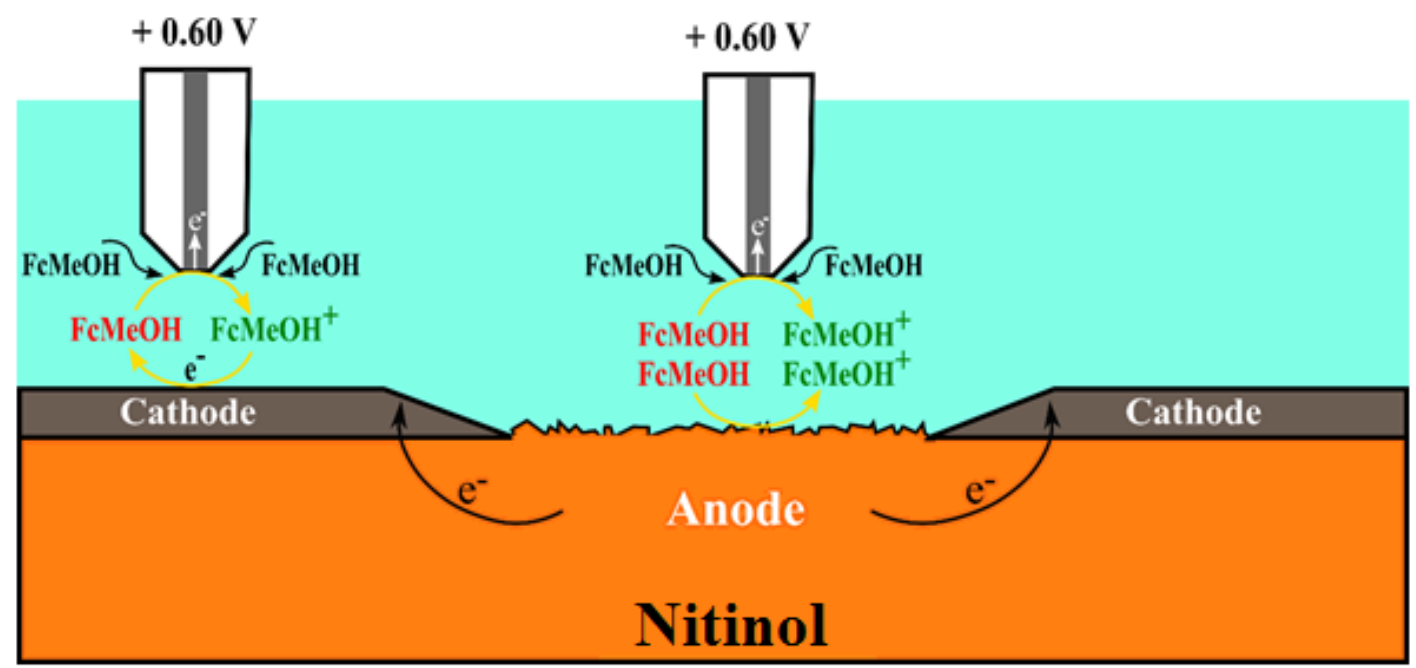

Figure 8

Sketch depicting the electrochemical processes associated to the electrochemical conversion of the redox mediator that occurred on the actively corroding nitinol surface produced after anodic polarization at $+1.00 \mathrm{~V}$ for $15 \mathrm{~min}$. 

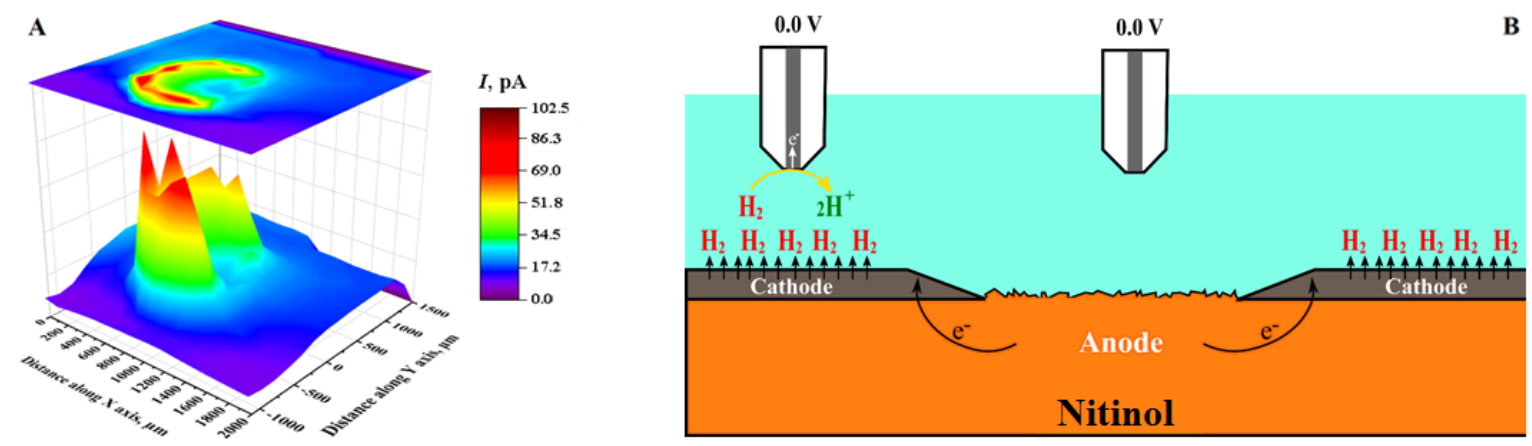

Figure 9

(A) SECM imaging of a nitinol sample after polarization at $+1.00 \mathrm{~V}$ vs. $\mathrm{Ag} / \mathrm{AgCl} /(3 \mathrm{M}) \mathrm{KCl}$ for 15 min during immersion in $0.1 \mathrm{M} \mathrm{NaCl}$ solution. Tip diameter: $15 \mu \mathrm{m}$; tip-sample distance: $10 \mu \mathrm{m}$; tip potential: $0.0 \mathrm{~V} \mathrm{Ag} / \mathrm{AgCl} /(3 \mathrm{M}) \mathrm{KCl}$; scan rate: $20 \mu \mathrm{m} \mathrm{s}^{-1}$. (B) Sketch depicting the electrochemical processes associated to the sample generation-tip collection operation that occurred on the actively corroding nitinol surface produced after anodic polarization at $+1.00 \mathrm{~V}$ for $15 \mathrm{~min}$.

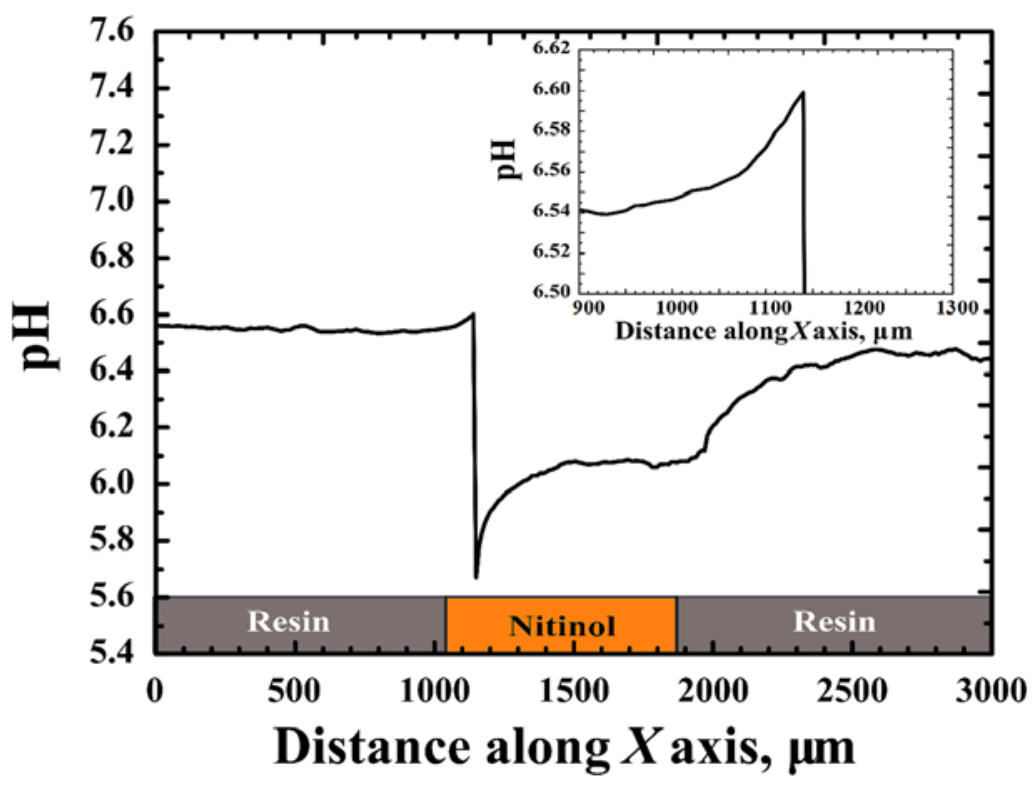

Figure 10

Potentiometric SECM line scan imaging of a nitinol sample after polarization at $+1.00 \mathrm{~V}$ vs . $\mathrm{Ag} / \mathrm{AgCl} /(3 \mathrm{M}) \mathrm{KCl}$ for 15 min during immersion in $0.1 \mathrm{M} \mathrm{NaCl}$ solution. The line scan was recorded along the $X$ axis passing over the center of the metal sample in the $Y$ direction using a $\mathrm{pH}$-sensitive $\mathrm{Sb} / \mathrm{Sb}_{2} \mathrm{O}_{3}$ microelectrode. Tip diameter: $30 \mu \mathrm{m}$; tip-sample distance: $20 \mu \mathrm{m}$; scan rate: $10 \mu \mathrm{m} \mathrm{s}^{-1}$. 


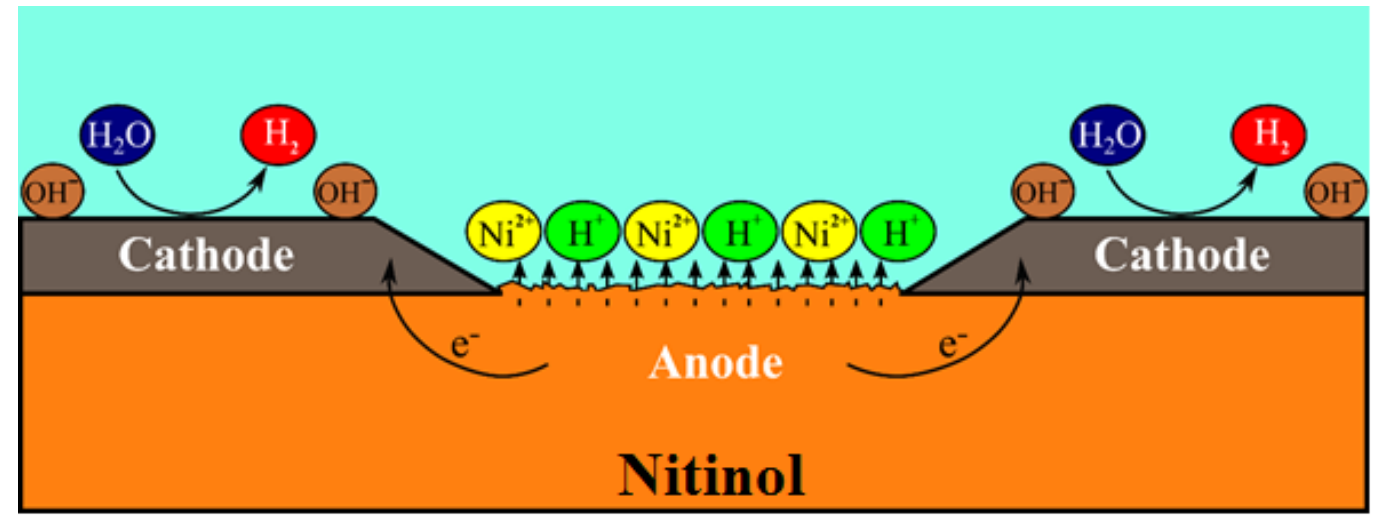

Figure 11

Sketch depicting the reactions accounting for the corrosion processes occurring on the nitinol surface remaining after anodic polarization at $+1.00 \mathrm{~V}$ vs. $\mathrm{Ag} / \mathrm{AgCl} /(3 \mathrm{M}) \mathrm{KCl}$ for $15 \mathrm{~min}$. 